\title{
Using trace elements to identify the geographic origin of migratory bats
}

\author{
Jamin G Wieringa ${ }^{\text {Corresp., } 1,2}$, Juliet Nagel ${ }^{3}$, David M Nelson ${ }^{3}$, Bryan C Carstens $^{1}$, H Lisle Gibbs ${ }^{1,2}$ \\ 1 Department of Evolution, Ecology, and Organismal Biology, The Ohio State University, Columbus, OH, United States \\ 2 Ohio Biodiversity Conservation Partnership, Columbus, Ohio, United States \\ 3 University of Maryland Center for Environmental Science, Appalachian Lab, Frostburg, Maryland, United States \\ Corresponding Author: Jamin G Wieringa \\ Email address: wieringa.3@osu.edu
}

The expansion of the wind energy industry has had benefits in terms of increased renewable energy production but has also led to increased mortality of migratory bats due to interactions with wind turbines. A key question that could guide bat-related management activities is identifying the geographic origin of bats killed at wind-energy facilities. Generating this information requires developing new methods for identifying the geographic sources of individual bats. Here we explore the viability of assigning geographic origin using trace element analyses of fur to infer the summer molting location of eastern red bats (Lasiurus borealis). Our approach is based on the idea that the concentration of trace elements in bat fur is related through the food chain to the amount of trace elements present in the soil, which varies across large geographic scales. Specifically, we used inductively coupled plasma - mass spectrometry to determine the concentration of fourteen trace elements in fur of 126 known-origin eastern red bats to generate a basemap for assignment throughout the range of this species in eastern North America. We then compared this map to publicly available soil trace element concentrations for the U.S. and Canada, used a probabilistic framework to generate likelihood-of-origin maps for each bat, and assessed how well trace element profiles predicted the origins of these individuals. Overall, our results suggest that trace elements allow successful assignment of individual bats $80 \%$ of the time while reducing probable locations in half. Our study supports the use of trace elements to identify the geographic origin of eastern red and perhaps other migratory bats, particularly when combined with data from other biomarkers such as genetic and stable isotope data. 
1 Using trace elements to identify the geographic origin of migratory bats

2

3 Jamin G. Wieringa*1,2 ${ }^{*}$ Juliet Nagel $^{3}$, David M. Nelson ${ }^{3}$, Bryan C. Carstens ${ }^{1}$, H. Lisle Gibbs ${ }^{1,2}$

4

5 1. Department of Evolution, Ecology and Organismal Biology, The Ohio State University, 6 Columbus, $\mathrm{OH}, \mathrm{USA}$

7 2. Ohio Biodiversity Conservation Partnership, Columbus, OH, USA

8 3. University of Maryland Center for Environmental Science, Appalachian Lab

10 Corresponding author:

11 Jamin G. Wieringa ${ }^{1,2}$

12

13 Email address: wieringa.3@osu.edu 


\section{Abstract}

15 The expansion of the wind energy industry has had benefits in terms of increased renewable energy production but has also led to increased mortality of migratory bats due to interactions

17 with wind turbines. A key question that could guide bat-related management activities is

18 identifying the geographic origin of bats killed at wind-energy facilities. Generating this

19 information requires developing new methods for identifying the geographic sources of individual bats. Here we explore the viability of assigning geographic origin using trace element analyses of fur to infer the summer molting location of eastern red bats (Lasiurus borealis). Our approach is based on the idea that the concentration of trace elements in bat fur is related through the food chain to the amount of trace elements present in the soil, which varies across large geographic scales. Specifically, we used inductively coupled plasma - mass spectrometry to determine the concentration of fourteen trace elements in fur of 126 known-origin eastern red bats to generate a basemap for assignment throughout the range of this species in eastern North America. We then compared this map to publicly available soil trace element concentrations for the U.S. and Canada, used a probabilistic framework to generate likelihood-of-origin maps for each bat, and assessed how well trace element profiles predicted the origins of these individuals. Overall, our results suggest that trace elements allow successful assignment of individual bats $80 \%$ of the time while reducing probable locations in half. Our study supports the use of trace elements to identify the geographic origin of eastern red and perhaps other migratory bats, particularly when combined with data from other biomarkers such as genetic and stable isotope data. 
37 It is estimated that across North America, up to 70 bats per turbine are killed each year (Cryan 38 2008), totaling $\sim 600,000$ bat casualties annually (Hayes, 2013). Based on the number of fatalities of hoary bats (Lasiurus cinereus) occurring at wind farms, Frick et al. (2017) projected that, in 50 years, the population size of this species may decline by up to $90 \%$. Other results (e.g. Rodhouse et al. 2019) support this prediction, highlighting the threat that the expansion in renewable wind energy represents to bats (Kunz et al., 2007a). The majority of the bats killed at wind farms in North America are from three migratory species (eastern red bat; Lasiurus borealis, hoary bat; L. cinereus, and silver-haired bat; Lasionycteris noctivagans; Kunz et al., 2007a). Given that the vast majority of bats killed at wind farms are from migratory species, it has been hypothesized that migratory behavior per se may contribute to their susceptibility due to the fact that they encounter multiple wind facilities during seasonal movements (Cryan \& Barclay, 2009). In support of this idea, bat mortality in North America at turbines has a strong seasonal component, with most deaths occurring during the late summer-fall migration period (Arnett et al., 2008).

One consequence of turbine impacts on migratory bats is that it raises questions about the geographic scale over which bat populations could be affected. Specifically, are impacts primarily on local summering populations or, as a result of migratory behavior, more wideranging (Voigt et al., 2012)? To answer this question, an essential piece of information that is needed is the geographic origin of the individuals killed at specific wind farms. This can then be used to address two important questions: First, as stated above, are bats killed at specific sites from local summering populations or migrants and, second, if they are migrants where did they

\section{Introduction}


58 originate in terms of their summer locations? Such information may inform mitigation efforts

59 and/or decisions about the siting of future wind farms (Kunz et al., 2007b).

60

61

62

63

64

65

66

67

Accomplishing these goals requires methods for sourcing individual bats to particular geographic locations. At present, few methods exist to generate this information. Techniques such as banding, GPS loggers and transmitters, and large-scale citizen science initiatives have been successfully used to source other migratory animals (Hobson et al., 2019a), yet are largely inapplicable to North American migratory bats. For example, bats are rarely banded as this activity was ended in the 1970s (Ellison, 2008) and now is only commonly used for species that are endangered or threatened (e.g. Ohio Bat Conservation Plan, 2018). GPS loggers require recapture of individuals, which is uncommon in many of these species (Schorr, Ellison \& Lukacs, 2014), and most transmitters are too heavy for use in these small flying organisms (Kays et al., 2015). Lastly, due to the nocturnal behavior of bats, citizen science initiatives similar to eBird (Sullivan et al., 2009) are limited in scope.

One class of potentially useful markers that have been underutilized to date are intrinsic biomarkers such as stable isotopes, genetic loci and trace elements. Biomarkers offer advantages such as absence of bias to site of marking (i.e. biased due to banding at one location), relatively low cost, a lack of impact on behavior, and small sample-size requirements (Hobson et al., 2019a, Vander Zanden et al. 2018). However, relative to the use of such approaches to document migratory behavior of birds (Norris \& Marra, 2007; Irwin, Irwin \& Smith, 2011; Hobson et al., 2014, Nelson et al., 2015), the use of biomarkers to track migration in migratory bats is relatively unexplored. To date, the most common type of biomarker used in bats has been stable hydrogen isotopes, which has provided some insights to their migratory behaviors (e.g. Cryan et al., 2004; Fraser et al., 2012; Ossa et al. 2012; Fraser, Brooks \& Longstaffe, 2017; Lehnert et al., 2018). 
81 However, hydrogen isotopes are most useful for identifying broad patterns of latitudinal or

82 elevational migration, whereas they are less useful along longitudinal gradients (Voigt \&

83

84

85

86

87 Lehnert, 2019). As a result, other markers are needed, either as standalone biomarkers or for use in conjunction with isotopes (Hobson et al., 2019b).

Trace elements represent a class of biomarkers successfully used in birds and other species (Poesel et al., 2008; Szép et al., 2009; Ethier, Kyle \& Nocera, 2014; Flache et al., 2015a; Tigar \& Hursthouse, 2016) and so would seem to have potential for sourcing bat movements. Due to differences in the geological history, spatial variation in the concentrations of elements exists across the continental U.S. and Canada (Smith et al., 2008). The amount of an element incorporated into tissue of an organism partly depends on the amount of the element present in the soil in the area as each element travels through the food web (Ethier et al., 2013). Individuals who forage in the same geographic area are thus expected to exhibit greater similarities in their elemental profiles (Orłowski et al., 2016). This type of geographic pattern has been documented in other animals, including humans (Oyoo-Okoth et al., 2012), birds (Burger et al., 2001), nonhuman mammals (Either et al., 2014), and insects (Tigar \& Hursthouse, 2016). This pattern has also been demonstrated in some species of non-migratory bats in relation to the concentrations of mercury (Chetaelat et al., 2018), although Hernout et al. (2016) did not find support for this idea in some species of bats for a limited number of elements. Since migratory bats undergo a yearly molt during the summer (Cryan et al., 2004; Britzke et al., 2009; Sullivan et al., 2012; Fraser et al., 2012; Fraser, Longstaffe \& Fenton, 2013; Pylant, Nelson \& Keller, 2014; Flache et al., 2015b), it seems likely that trace elements in their fur should reflect their summering locations.

Here, we investigated the possibility of using trace elements to determine the geographic source of individual bats. Our goals were to: 1) Determine the feasibility of using trace elements 
104 to source eastern red bats (L. borealis) from different locations from across their range to their 105 summering location; and 2) Provide a basemap and methods for studies seeking to use this 106 methodology. We then compare the precision and accuracy of trace element assignment to other

107 previously studied biomarkers. Our aim is to identify and validate a new class of biomarkers that 108 can be helpful in assessing the geographic scale across which wind farms may impact bat 109 populations.

\section{Methods}

Soil Data Collection

112 To generate a trace element basemap, data on trace element composition of soil were collected

113 from the U.S. Geological Survey (USGS) and Natural Resources Canada (NRC) online databases

114 available at https://mrdata.usgs.gov/soilgeochemistry/\#/summary and

115 https:/www.nrcan.gc.ca/home, respectively. We used data that had originally been collected as

116 part of a continent-wide low-density geochemical cooperative survey between USGS, NRC, and

117 Mexican Geological Survey (Smith et al., 2005; 2014) since previous studies have found little

118 difference between sampling at low-density and high-density on soil trace element interpolation

119 (Birke, Rauch \& Stummeyer, 2016). However, we were only able to access data for U.S. and

120 Canada. Details of the sampling techniques are found in Smith et al. (2014). In brief, 4857 low

121 density sites (1 site per $1600 \mathrm{~km}^{2}$ ) were selected and samples collected from soil layers of $0-5 \mathrm{~cm}$,

122 Soil A (topsoil), and Soil B+C composite (deeper soil up to $1 \mathrm{~m}$ ). We used trace element

123 concentration from Soil $\mathrm{B}+\mathrm{C}$ composite samples to minimize the effects of potential surface

124 contaminants (Sastre et al., 2001). Elements selected for analysis were the same as those chosen

125 for analysis in fur samples (see below for inclusion criteria) and included Aluminum (Al), Nickel 
126 (Ni), Copper (Cu), Rubidium (Rb), Yttrium (Y), Molybdenum (Mo), Tin (Sn), Barium (Ba),

127 Cesium (Cs), Cerium (Ce), Mercury (Hg), Magnesium (Mg), Manganese (Mn), and Iron (Fe).

128 Fur Analysis

129 To validate the use of trace elements for sourcing individual bats it is necessary to link a resident

130 bat's fur elemental profile to that of a specific geographic region. To accomplish this, we used

131 fur samples from eastern red bats collected from on axillary region of 126 museum specimens

132 from the Smithsonian National Museum of Natural History that had previously been used for a

133 similar purpose in an isotope validation study (Pylant, Nelson \& Keller, 2014; Fig. 1).

134 Permission to use these samples in this study was granted by the Smithsonian (Wieringa, pers.

135 comm.). Following guidelines from isotopic studies (Cryan, Stricker \& Wunder, 2014), we

136 assume these samples are representative of the element profiles of local bats because these

137 samples were collected during the summer, presumably after molting and prior to fall migration

138 (Fraser, Longstaffe \& Fenton, 2013). We assume that the fur collected was grown at or near the

139 sampling location. To sample each individual, fur sample was clipped from the torso of each bat

140 and placed inside $2 \mathrm{ml}$ centrifuge tubes for storage until later use.

141 To prepare samples for trace element analyses, individual fur samples were processed

142 following methods in Flache et al. (2015a) and Hickey et al. (2001). Specifically, each sample

143 was cleaned with Triton-X (1:400) and acetone, rinsed with reagent grade water and dried at 60

$144{ }^{\circ} \mathrm{C}$ in a sterile Low Density-Polyethylene (LDPE) tube. Gold chloride $\left(\mathrm{AuCl}_{3}\right)$ was then added at

$1451 \mathrm{ppm}$ final concentration as a mercury stabilizer (USEPA, 2003). We then added $1 \mathrm{ml}$ of $\mathrm{HNO}_{3}$

146 and placed tubes on a heating block at $70{ }^{\circ} \mathrm{C}$ for 1 hour to ensure complete fur digestion.

147 Samples were then allowed to cool to room temperature, after which $10 \mathrm{ppb}$ final concentration 
148 Indium was added as an internal standard, and samples were then diluted with reagent grade 149 water to $10 \mathrm{ml}$.

To more accurately determine trace element concentrations, we used a narrow range

151 calibration curve (calibrations limited to only expected range) as determined from concentrations

152 of previous analyses (Table S1). To create our calibration curve, 5 bat fur samples were analyzed 153 using ThermoFinnigan Element 2 High Resolution ICP-MS at the Trace Element Research Lab 154 (TERL) at Ohio State using the Semi-Quantitative mode (Chen et al., 2008; Table S1). This 155 mode allows for rapid quantification of all elements through estimating only a few elements 156 accurately and inferring the rest on previously determined ratios. While there is increased error, 157 this method of analysis allows for rapid quantification to assess which elements to use in further analysis. When compared to blanks, these 5 samples identify elements that were reliably detected above background and gave concentrations that were used to create narrow range calibration standards. This more rapid analysis allowed us to better determine which concentrations to expect for more in-depth determination (below) which created more accurate calibration curves, and allows for better determination of concentrations. make additional elemental concentration measurements. Samples were fed into the ICP-MS with a delay before reading to reduce the chance of carry over effects, followed by a short wash between each sample. Samples were then ionized in plasma and the concentrations determined when compared to a calibration curve. After every 10-15 samples, one of the calibration standards used to create the calibration curve and a blank were re-analyzed to ensure accuracy of our results. Additionally, ten samples were re-run to determine analytical variation. We used 
170 software included with the ICP-MS to correct each sample to the values for the internal standard

171 and further corrected sample concentrations based on the mass of the fur used.

172 Statistical Analyses

173 Key steps in our statistical analyses were as follows: 1) Summarize trace element variation

174 among individual bat fur samples using spatially explicate measures; 2) Link fur and soil

175 elemental concentrations across the range of this species; 3) Generate a basemap across the

176 species range; 4) Assign individuals to origin, and assess the accuracy and precision of

177 assignment.

178 Summarizing Individual Variation

179 Sourcing individuals via their trace element profiles requires summarizing the spatial correlation

180 of trace elements among individuals sampled (Donovan et al., 2006). Therefore, we used sPCA

181 scores to summarize variation for bat fur concentrations using the function 'gwpca' in the

182 'GWmodel' package in R (Gollini et al., 2015). sPCA introduces a spatially based weighting

183 matrix into the PCA matrix. The advantage of sPCA over traditional PCA is that sPCA

184 maximizes spatial autocorrelation, and therefore shows strong spatial relationships in the first

185 few principle axes. When using 'gwpca' we generally applied the default values in the package,

186 with the exception that bandwidth was determined using the 'bw.gwpca' function. This function

187 plays an important role in the weighting function of the sPCA. The loadings were then used to

188 determine the principle component scores based on element profiles for individual bats. These

189 values could then be used for geographic assignment; both for creating a basemap, and validating

190 their use.

191 Linking Fur and Soil Trace Element Values

Peer) reviewing PDF | (2020:03:47168:1:1:NEW 3 Aug 2020) 
192 We first tested the assumption that element values from fur reflect values in the soil from the

193 same geographic location. To do this we generated linear models for individual and multivariate

194 measures of element abundance which estimated the relationship between soil element

195 concentration (extracted from maps in Smith et al., 2014) and fur element concentration. This

196 was accomplished using the function ' $\mathrm{lm}$ ' in R (R Core Team, 2019). The usefulness in

197 assignment was assessed by the amount of variation explained by the linear model $\left(\mathrm{R}^{2}\right)$ and the

198 significance of the relationship. However, we found weak relationships for individual elements,

199 which precludes the use of single elements for assignment. Weak univariate relationships does

200 not, necessarily, preclude significant multivariate relationships from being present. In which

201 case, principle components generated above may capture patterns of variation across multiple

202 elements that are useful for assignment. To assess the ability of use of a composite metric

203 (principle components), we compared predicted and actual values of PCs, and compared soil to

204 hypothetical fur to PCs (described below) to actual fur PC values.

205 Geographic Assignment

206 We used methods developed for sourcing species using hydrogen isotope values of fur (e.g.

207 Pylant et al., 2016) to conduct geographic assignment analyses. We created a basemap of

208 multivariate estimates of fur values in ArcMap 10.6, after removing outliers using squared robust

209 Mahalanobis distances and evaluating plotted values (Ethier, Kyle \& Nocera, 2014). When

210 creating our base map, we used two methods to generate two distinct portions of the base map

211 (Fig. S1). The first portion was restricted to the geographic range of our samples (Figure 1;

$212 \sim 92 \%$ of range) and was determined using the first principle component value determined solely

213 from the fur concentrations of the 14 elements from our validation data set based on 111

214 samples. The other 15 samples were used for independent verification of the method (below). 
215 Wunder \& Norris (2019) characterized this type of model as one that directly links tissue

216 chemistry and geography. Fur principle component values were taken from the sPCA analyses,

217 with values interpolated between the locations of our bats using inverse distance weighting

218 (IDW). However, because this approach only uses fur concentrations from samples collected, we

219 are only able project to the limit of our points on a map which does not encompass the entire

220 range of the species (Fig. 1).

To extend our prediction coverage to the second portion ( $~ 8 \%$ of range; Fig. 1$)$ of our

222 base map for which no bat samples were available we related soil element concentration to the

223 fur concentrations within the first portion that covered all sampled points. Using those

224 relationships, we transformed soil concentration outside of the sampling extent to hypothetical

225 fur concentrations (Fig. S1). Using the sPCA loadings determined previously, we then

226 transformed the hypothetical fur to PC1 values. Wunder \& Norris (2019) describe this approach

227 as an indirectly linked tissue chemistry and geography method. This method is less accurate as

228 more noise is present in the samples due to elemental concentrations being filtered through the

229 food web from soil to fur. As the two maps (directly linked and indirectly linked tissue and

230 geography) do not overlap at any point, they were then merged to create one continuous joint

231 projection across the U.S. and Canada. There was a slight misalignment between the two

232 portions which was left in place to preserve the more accurate direct fur-to-fur comparison

233 present in the base maps generated. Additionally, we tested all metrics for assignment (below)

234 using both the merged maps and the direct geographic relationship (portion 1) separately to

235 ensure adding the second portion did not impact our results.

236 When generating our base maps we used a leave-three-out (n-3) approach for cross

237 validation. For each process in creating the base map, n-3 samples were used, leaving 3 samples 
238 to be assigned back to the base map and testing the performance of our model. This was repeated

239100 times, allowing us to assess how our analysis will translate to an independent dataset. When

240 assigning individual bats back to their origin, we used methods originally used in assigning

241 migratory species using hydrogen isotopes values present in bird feathers and bat fur (Fraser et

242 al., 2012; Tonra, Both \& Marra, 2014; Fraser, Brooks \& Longstaffe, 2017). We did this using the

243 normal probability density function as given in the following equation (Tonra, Both \& Marra,

244 2014):

245

246

$f\left(y^{*} \mid \mu_{i}, \sigma\right)=\frac{1}{\sigma \sqrt{2 \pi}} e^{-\frac{\left(y^{*}-\mu_{j}\right)^{2}}{2 \sigma^{2}}}$

247

where $f\left(y^{*} \mid \mu_{i}, \sigma\right)$ is the likelihood that an individual with a given principle component fur value

$\left(y^{*}\right)$ originated from cell $i, \mu_{i}$ is the predicted sPCA value of cell $i$, and $\sigma^{2}$ is the variance ( $\sigma$

equaling the standard deviation) within a sampling area which was set at the standard deviation

of residuals from the regression between predicted and actual values $\left(\sigma^{2}=9.696\right)$. The result of

252

this equation is the probability, given a measured fur PC value, came from the cell in question,

ranging from 0 to 1 . We then iteratively analyzed every cell $\left(0.16^{\circ} \times 0.16^{\circ} ; \sim 315 \mathrm{~km}^{2}\right)$ of each

base map for all individuals and determined the probability a given individual originated from all cells present on the base map.

To evaluate the quality of our model we estimated the probability of assignment for the location where the sample had been collected and considered a prediction $\geq 50 \%$ as correct. We chose $50 \%$ as our cut off because we prioritized accuracy (i.e. a correct prediction) above precision (i.e. reducing area of prediction). However, we also evaluated cut-offs of $66 \%$ and $75 \%$ 
260 accuracy as have been used previously (Tonra, Both \& Marra, 2014; Seifert et al., 2018). Finally,

261 due to the volant nature of these species, if the prediction value at the sampling location was

262 below 50\%, we checked if a point within $10 \mathrm{~km}$ (potential nightly travel distance from roost;

263 Hayes \& Wiles, 2013) was above our threshold. If a point within $10 \mathrm{~km}$ was above our 50\%

264 threshold, we also considered this a correct assignment to account for the possibility of nightly

265 bat movement around the capture location.

266 Independent Fur Sample Validation

267 For further validation we used a subset of random samples from the original $126(n=15)$ that had

268 not been used in base map generation or the leave-three-out analysis. Our logic was that if

269 samples that are independent from the rest of the analyses can also be accurately sourced to their

270 inferred location of origin, it supports the claim that this method can be applied to all L. borealis

271 and can be used in future analyses. Each sample's fur trace element concentrations were

272 transformed given the sPCA component values previously determined and assigned to a

273 geographic area following the same protocol above.

\section{Results}

\section{Trace Element Concentrations}

276 Concentrations of trace elements in the fur of eastern red bats are similar to values previously

277 reported in fur of other bats (Table 1; for detailed summary see Table S2; Hickey et al., 2001;

278 Zocche et al., 2010; Flache et al., 2015a; Flache et al., 2015b); in addition, levels of variation

279 (reported as SD of mean concentrations) were also similar,. Overall, there is a high level of

280 variation in trace element concentrations present among individual samples with all elements

281 having a standard deviation greater than $50 \%$ of the mean (Table 1). This suggests that values for 
282 individuals collected from different locations differ greatly, which increases the likelihood of

283 correctly assigning individual bats to source areas.

284 Linking Fur and Soil Element Values

285 All individual elements showed only weak correlations between element values in fur and in the 286 soil with all $\mathrm{R}^{2}$ values $<0.16$ and only three showing a statistically significant relationship $(\mathrm{P}<$

287 0.05) (Table 1). This means that individual elements are unlikely to provide sufficient resolution 288 for sourcing individual bats.

Next, we explored the use of composite measure that used multivariate approaches to combine data from different elements in fur. We used a spatial principle component analysis (sPCA) approach to reduce the number of variables from 14 elements to a set of spatial weighted principle component values. We first used Kaiser criterion to evaluate our principle components (PC) from our sPCA from 'gwpca' in R (Gollini et al., 2015), with the recommendation to drop PCs with an eigen value below 1.0. By only retaining PCs with eigenvalues above 1.0, we retain factors that extract at least as much information as an equivalent single variable (Kaiser, 1960). In addition, we examined the percent of variation explained by each principle component value. PC 1 explained $50 \%$ of the variation present in our data with PC 2 only adding $12 \%$ variation explained (Table 2). PCs 3 and larger also added very little to the cumulative variation explained (Table 2). As a consequence, we chose to only retain PC 1 for further analyses. Examination of the first PC shows $\mathrm{Al}, \mathrm{Cu}, \mathrm{Ba}, \mathrm{Mg}$, and $\mathrm{Fe}$ had the largest absolute weights (PCA loadings multiplied by average fur element values) on PC 1 relative to their means and weight times mean 302 greater than or equal to 1. 
304 due to similar elemental concentrations in areas that are geographically separated from each

305 other. This indicates that global spatial structures exhibited by elements are not likely due to

306 random variation. To determine if the PC1 values offer a better way to assign individual bats

307 than single elements we compared predicted to actual PC values using a linear model. The PC1-

308 based model had an $\mathrm{R}^{2}=0.5(\mathrm{p}<0.001)$ which is much higher than the values for individual

309 elements. Consequently, we used PC1 values as our measurement of element variation in

310 subsequent analyses.

311 Geographic Assignment Using Trace Elements

312 To assess our ability to conduct the geographic assignment of individual bats, we explored three

313 distinct but related factors: Accuracy, precision, and geographic patterns. Accuracy is defined by

314 the ability to correctly assign an individual to their origin. Precision is assessed by the amount of

315 area determined as being probable as an area of origin (less area predicted equals higher

316 precision). Finally, geographic patterns are patterns that follow an ordered arrangement through

317 space (e.g. a north/south gradient).

318 To explore these aspects of our ability to do assignments for the independent dataset, after 319 generating our leave-three-out assignment, we combined the averaged basemaps into one single

320 basemap surface (Fig. 2). Extending our base maps by relating soil to hypothetical fur to

321 principle component values showed a correlation of 0.24 between direct and indirect base map

322 generation. Further, when creating our base maps we compared the merged raster and direct

323 geographic assignment; both showed similar results (accuracy remained consistent, precision

$324 \pm 1 \%)$ and so we used the merged basemap for assignment. 
326 We measured accuracy as the number of individuals with a probability over 0.5 or being within

$32710 \mathrm{~km}$ of an area above 0.5 . Other threshold values $(0.66$ and 0.75$)$ that were tested resulted in 328 poor assignment accuracy (56\% and $49 \%$ correct) and so were not considered further. The 329 probability for the training dataset to be accurate at a $50 \%$ threshold was $81 \%$, and was

330 determined by the number of individuals above 0.5 using a leave-three-out analysis (Table 3 ).

331 Additionally, 12 of our 15 validation independent samples were either above $50 \%$ or within

$33210 \mathrm{~km}$ of a cell above our threshold, yielding an accuracy of $80 \%$ (Table 3 ). Because of bats

333 being able to fly $\sim 10 \mathrm{~km}$ from their roost in a given night to feed, we considered these correct

334 assignments. Therefore, using a threshold of 50\%, we correctly predict the sampling location

$335 \sim 80 \%$ of the time. Examples of a correct and incorrect assignment from our cross-validation

336 dataset are shown in Fig. 3 (all assignment maps from cross validation in Fig. S3; same order as 337 Table 3).

2. Precision

Precision for geographic assignment, or area predicted above 0.5 threshold compared to total area, is given in the Range Percent column in Table 3. Of note, if an individual was not correctly assigned they were not included in calculations of precision. When using the samples from the

342 leave-three-out testing and map generation, we on average, reduced the possible range by $51 \%$.

343 When using our 15 independent validation samples, for individuals that were predicted correctly, 344 our average prediction range is $47 \%$ (minimum: $22 \%$, maximum: $76 \%$ ) of the total possible 345 range these bats could have originated from. To summarize, when we have a bat from an 346 "unknown" origin, we can reduce on average the possible source locations for this individual by 347 over $50 \%$. 
349 Finally, while the precision of sample assignment was lacking for some samples (Table 3), we do

350 observe geographic variation. However, we do not observe a clear geographic pattern present in

351 other aspects of assignment accuracy when overlaying the boundaries of predicted sources (Fig.

352 S4). While this precludes use of trace elements to clearly delineate north/south or east/west

353 movements, when combined with other markers that exhibit these patterns trace elements could

354 add overall precision to assignment accuracy. This is especially true for hydrogen isotope

355 assignment probabilities, as the base map generated here is different from that for hydrogen

356 isotopes based on correlations done in $\mathrm{R}$ on values extracted from both maps from 150 random

357 locations $\left(\mathrm{R}^{2}=-0.13, \mathrm{p}=0.11\right)$.

\section{Discussion}

359 Our results show the promise of using trace elements to accurately assign individual bats back to their summer molting location. Specifically, we observe a correct assignment rate of $\sim 80 \%$ with

361 a reduction in predicted area of $\sim 50 \%$ from total range. It is important to consider that there is a

362 trade-off between accuracy and precision in that the number of correct predictions (true

363 positives) is inversely related to the number of incorrect absences (false positives). For example,

364 if we wished to increase the number of correctly predicted origins (accuracy), we would need to

365 increase the number of false positives predicted thereby decreasing our precision (Pearce and

366 Ferrier 2000). In concrete terms, if a bat originates near the edge of a predicted area, by

367 attempting to increase our precision (reduce prediction area) we could lose our ability to make a

368 correct prediction of the bats origin. In this study, we chose to emphasize accuracy because for

369 species with conservation implications it is often times true that accuracy is more important 
370 (Allouche, Tsoar, \& Kadmon, 2006). In other words, it is better to know where an individual is 371 than to identify a smaller range that may not be correct.

Our analyses make several key assumptions. The most important is that the fur of a sampled bat was grown at (or very near to) the sampling location, hence the element profile matches that of a particular location. As noted previously, eastern red bats are known to molt during the summer (Fraser, Longstaffe \& Fenton, 2013) within a relatively short time frame, and as a result we assume that fur is grown where they spent their summers. As such, it is reasonable to assume that the bats used in this study were captured near the location where they grew new fur. Second, we only used samples that had confirmed geographic origins using isotope analysis (Pylant, Nelson \& Keller, 2014). Both these features of the samples we used to validate our method make us confident our assumption about the geographic origin of our fur samples is accurate. tissue of various bat species to track bioaccumulation (Hickey et al., 2001; Flache et al., 2015;

Rahman, Talukdar \& Choudhury 2020). For example, Chételat et al. (2018) showed a correlation between the atmospheric mercury in Canada and the concentration present in the fur of a nonmigratory bat, supporting the notion of the use of mercury levels to source bats. We examined in fur and geographic location (Fig. S2). More broadly, the use of trace elements to geographically source individuals has been successful in other species such as badgers (Ethier, 
We focused on a single bat species, but our results highlight the possibility of using trace

394

395

396

397

398

399

400

401

402

403

404

405

406

407

408

409

410

411

412

413

414

415

elements to source individuals in other species of migratory bats because of their similar life

history features (Harvey, Altenbach \& Best, 2011). Due to the broader or similar diet in other

insectivorous migratory bat species, we suspect that we may find better resolution for other species (Hickey, Acharya \& Pennington, 1996; Chételat et al., 2018) because a broader diet is

likely to better reflect the trace element profile of a particular location due to an increased range of element sources from prey (e.g. Chételat et al., 2018). We expect that due to the similar diets between eastern red bats and hoary bats (Newbern \& Whidden, 2019) that this method will be applicable to hoary bats with the same level of assignment accuracy. Wilson (2017) furthered showed no significant difference in diet between hoary and eastern red bats, demonstrating that lack of statistically different diets is widespread across the range (Pennsylvania [Newbern \&Whidden, 2019] and Kansas [Wilson 2017]). Newbern and Whidden (2019) also found that silver-haired bats had a different and broader diet than hoary and eastern red bats, indicating that the method may work better for this species due to their broader diet.

In terms of diet stability over time and its potential impacts on element profiles, while dietary preference switches are known to occur in eastern red bats these shifts take place just prior to or during migration (Hayes et al. 2019), indicating a relatively stable diet over a summer molting period hence minimal impacts on element variation as assayed here. Some other species, such as hoary bat, do not appear to shift their diet during summer (Reimer, Baerwald \& Barclay, 2010) suggesting minimal impacts on element profiles.

Finally, elemental sourcing is likely applicable to bats on other continents where substantial numbers of the individuals killed by wind turbines are migrant species (e.g. Europe Lehnert et al. 2014) with similar diets (Vaughan 1997), and an availability of soil data on 
416 element abundance (Birke, Rauch \& Stummeyer, 2014). However, we also note that because the

417 specific characteristics of elemental uptake can vary between even closely related species, the

418 use of elements for sourcing individuals needs to be validated for each species (Wunder \&

419 Norris, 2019), as is similar to other biomarkers.

Two other classes of biomarkers that have been evaluated for use in sourcing bats are

421

422

423

424

425

426

427

428

429

430

431

432

433

434

435

436

437

438 genetic markers and stable isotopes. To date, three studies have attempted to determine the

feasibility of using genetic markers by looking for genetic structuring (Vonhff \& Russell, 2015;

Pylant et al., 2016; Sovic, Carstens \& Gibbs, 2016). However, none of these studies have found structuring for the three species of migratory bats in North America. Currently, studies are underway to determine the feasibility of using other types of genetic markers for sourcing bat include whole genome sequencing (J. Wieringa et al., in prep.) and genotyping by sequencing (GBS) (J Nagel et al, in prep.).

In contrast, stable isotopes (mainly hydrogen) have shown more promise for determining origins of latitudinal migratory bats (e.g. Pylant et al., 2016). Depending on the region, accuracy of assignment for isotopes can range from $\sim 50 \%$ to $90 \%$ with reasonable precision (PopaLisseanu et al., 2012), which is comparable to the accuracy of the trace elements used here, although isotopes have higher precision than trace elements $(\sim 33 \%-50 \%$ vs $50 \%$ of range, respectively; Ruegg et al., 2017). Both trace elements and isotopes require the same type and roughly same amount of sample, but trace elements cost slightly higher ( $\sim 15$ vs $\$ 25$ per sample; Wieringa, pers. comm.). Finally, an important difference in the information that each marker type yields is that trace elements provide geographical sourcing along both longitudinal and latitudinal gradients, depending on region, whereas isotopes provide discrimination primarily along latitudinal gradients (Hobson et al., 2019b).

Peer) reviewing PDF | (2020:03:47168:1:1:NEW 3 Aug 2020) 
productive way to identify the geographic origins on individual bats as has been shown to be the

441

442

443

444

445

446

447

448

case for birds (Hobson et al., 2019b). For example, in other bat species the use of multiple markers enabled levels of accuracy to be maintained while reducing the area of residence predicted for individuals (Popa-Lisseanu et al., 2012). In some bird species, combining isotopes with trace elements has been shown to be more effective in sourcing individuals to specific locations than using data from just one type of marker (Gómez-Díaz \& González-Solís, 2007). Finally generating occupancy prior surfaces based on Species Distribution Models (SDMs) may also be useful as not all locations are equally likely to be a source for a given individual due to environmental differences across space (Cryan, Sticker \& Wunder, 2014). Statistical approaches, such as cross-validation calibrated combined model tuning, in which probability surfaces based on SDMs, and data from trace elements, isotopes, and possibly genetics are combined offer a way to incorporate distinct information from different markers to generate a single assignment probability for a given sample (Rundel et al., 2013).

We emphasize that using approaches such as trace element analyses to mitigate wind turbine impacts on bats has economic as well as population-related benefits. Across the United States, all bats, including eastern red bat, contribute $>\$ 3.7$ billion annually to the economy through the consumption of pest insects (Boyles et al., 2011). Multiple studies have found economically important pest species in the stomachs of eastern red bats (e.g. Clare et al., 2009), including gypsy months, tent caterpillars, and cutworms. Tools such a trace elements can aid in mitigating these projected declines of migratory bat populations due to wind energy impacts and preserving these benefits (Frick et al., 2017).

\section{Conclusion}

Peer) reviewing PDF | (2020:03:47168:1:1:NEW 3 Aug 2020) 
462 To advance migratory bat conservation, it is vital that we understand their migration patterns

463 (Kunz et al., 2007b). Identifying patterns of movement would allow planning the locations of

464 wind farms to mitigate impacts on bat populations (Cryan, Stricker \& Wunder, 2014). This

465 information could also be used to set standards for "smart" curtailment (Hayes et al., 2019) to

466 reduce mortality and better plan future developments in wind energy that minimize placement in

467 movement corridors. Toward this goal, we find that trace elements are a viable method for

468 sourcing eastern red bat and this approach may be applicable to other migratory bat species. The

469 grand challenge in understanding migration is to know when, where, why, and how animals

470 migrate (Bowlin et al., 2010). Future studies need to explore not only the singular use of trace

471 elements as a sourcing method, but also the process of combining trace elements with multiple

472 potential sources of geographic information, such as isotopes, species distribution models, and

473 genetics to accomplish this goal.

\section{Acknowledgements}

475 We thank the Trace Element Research Lab (TERL) at The Ohio State University for their 476 assistance with the processing of samples. Specifically we thank Anthony Lutton for help with

477 scheduling lab equipment use and for help with interpreting our results and John Olesik and 478 other members of the TERL for general assistance. We also thank the Carstens and Gibbs labs in 479 the Department of EEOB at Ohio State for their advice and assistance with the editing of this 480 manuscript. Finally, we thank Erin Hazelton and Jonathan Sorg, Ohio Division of Wildife, for 481 assistance with grant administration. This work was supported by a grant (GRT00046616) from 482 the Competitive State Wildlife Grants Program to Ohio State University and the University of 483 Maryland Center for Environmental Science as jointly administered by the US Fish and Wildlife 484 Service, the Ohio Division of Wildlife and the Maryland Department of Natural Resources. This 
485 study is a contribution from the Ohio Biodiversity Conservation Partnership. Samples for this

486 project were provided by the Smithsonian Institution, National Museum of Natural History,

487 Division of Mammals. 


\section{References}

489 Allouche O, Tsoar A, Kadmon R. 2006. Assessing the accuracy of species distribution models:

490 prevalence, kappa and the true skill statistic (TSS). Journal of Applied Ecology 43: 1223-1232.

491 Arnett EB, Brown WK, Erickson WP, Fiedler JK, Hamilton BL, Henry TH, Jain A, Johnson GD,

492 Kerns J, Koford RR, Nicholson CP. 2008. Patterns of bat fatalities at wind energy facilities in

493 North America. The Journal of Wildlife Management 72: 61-78.

494 Arroyo-Cabrales J, Miller B, Reid F, Cuarón AD, de Grammont PC. 2016. Lasiurus borealis.

495 The IUCN Red List of Threatened Species 2016: e.T11347A22121017.

496 Baerwald EF, Patterson WP, Barclay RMR. 2014. Origins and migratory patterns of bats killed

497 by wind turbines in southern Alberta: evidence from stable isotopes. Ecosphere 5: 1-17.

498 Becker RA, Wilks AR, Brownrigg R, Minka TP, Deckmyn A. 2018. maps: Draw Geographical

499 Maps. R package.

500 Birke M, Rauch U, Stummeyer J. 2015. How robust are geochemical patterns? A comparison of

501 low and high sample density geochemical mapping in Germany. Journal of Geochemical

502 Exploration 154: 105-128.

503 Bowlin MS, Bisson IA, Shamoun-Baranes J, Reichard JD, Sapir N, Marra PP, Kunz TH,

504 Wilcove DS, Hedenström A, Guglielmo CG, Åkesson S. 2010. Grand challenges in migration

505 biology. Integrative and Comparative Biology 50: 261-279.

506 Boyles JG, Cryan PM, McCracken GF, Kunz TH. 2011. Economic importance of bats in

507 agriculture. Science 332: 41-42. 
508 Britzke ER, Loeb SC, Hobson KA, Romanek, CS, Vonhof MJ. 2009. Using hydrogen isotopes to

509 assign origins of bats in the eastern United States. Journal of Mammalogy 90: 743-751.

510 Burger J, Shukla T, Dixon C, Shukla S, McMahon MJ, Ramos R, Gochfeld M. 2001. Metals in 511 feathers of sooty tern, white tern, gray-backed tern, and brown noddy from islands in the North 512 Pacific. Environmental Monitoring and Assessment 71: 71-89.

513 Chen H, Dabek-Zlotorzynska E, Rasmussen PE, Hassan N, Lanouette M. 2008. Evaluation of 514 semiquantitative analysis mode in ICP-MS. Talanta 74: 1547-1555.

515 Chételat J, Hickey MBC, Poulain AJ, Dastoor A, Ryjkov A, McAlpine D, Vanderwolf K, Jung

516 TS, Hale L, Cooke EL, Hobson D. 2018. Spatial variation of mercury bioaccumulation in bats of

517 Canada linked to atmospheric mercury deposition. Science of the Total Environment 626: 668518677.

519 Clare EL, Fraser EE, Braid HE, Fenton MB, Hebert PD. 2009. Species on the menu of a 520 generalist predator, the eastern red bat (Lasiurus borealis): using a molecular approach to detect 521 arthropod prey. Molecular Ecology 18: 2532-2542.

522 Cryan, P.M., 2008. Mating behavior as a possible cause of bat fatalities at wind turbines. The 523 Journal of Wildlife Management 72: 845-849.

524 Cryan PM, Barclay RM. 2009. Causes of bat fatalities at wind turbines: hypotheses and 525 predictions. Journal of Mammalogy 90: 1330-1340.

526 Cryan PM, Bogan MA, Rye RO, Landis GP, Kester CL. 2004. Stable hydrogen isotope analysis 527 of bat hair as evidence for seasonal molt and long-distance migration. Journal of Mammalogy 528 85: 995-1001. 
529 Cryan PM, Stricker CA, Wunder MB. 2014. Continental-scale, seasonal movements of a

530 heterothermic migratory tree bat. Ecological Applications 24: 602-616.

531 Donovan T, Buzas J, Jones P, Gibbs HL. 2006. Tracking dispersal in birds: assessing the

532 potential of elemental markers. The Auk 123: 500-511.

533 Ellison L. 2008. Summary and analysis of the US government bat banding program. Publications 534 of the US Geological Survey, p.10.

535 Ethier DM, Kyle CJ, Kyser TK, Nocera JJ. 2013, April. Trace elements in claw keratin as

536 temporally explicit indicators of geographic origin in terrestrial mammals. Annales Zoologici

537 Fennici 50: 89-99.

538 Ethier DM, Kyle CJ, Nocera JJ. 2014. Tracking animal movement by comparing trace element

539 signatures in claws to spatial variability of elements in soils. Science of the Total Environment 540 468: 699-705.

541 Flache L, Becker NI, Kierdorf U, Czarnecki S, Düring RA, Encarnação JA. 2015a. Hair samples

542 as monitoring units for assessing metal exposure of bats: a new tool for risk

543 assessment. Mammalian Biology 80: 178-181.

544 Flache L, Czarnecki S, Düring RA, Kierdorf U, Encarnação JA. 2015b. Trace metal

545 concentrations in hairs of three bat species from an urbanized area in Germany. Journal of

546 Environmental Sciences 31: 184-193.

547 Fraser EE, McGuire LP, Eger JL, Longstaffe FJ, Fenton MB. 2012. Evidence of latitudinal 548 migration in tri-colored bats, Perimyotis subflavus. PLoSONE 7. 
549 Fraser EE, Longstaffe FJ, Fenton MB. 2013. Moulting matters: the importance of understanding

550 moulting cycles in bats when using fur for endogenous marker analysis. Canadian Journal of

551 Zoology 91: 533-544.

552 Fraser EE, Brooks D, Longstaffe FJ. 2017. Stable isotope investigation of the migratory behavior

553 of silver-haired bats (Lasionycteris noctivagans) in eastern North America. Journal of

554 Mammalogy 98: 1225-1235.

555 Frick WF, Baerwald EF, Pollock JF, Barclay RMR, Szymanski JA, Weller TJ, Russell AL, Loeb

556 SC, Medellin RA, McGuire LP. 2017. Fatalities at wind turbines may threaten population

557 viability of a migratory bat. Biological Conservation 209: 172-177.

558 Gollini I, Lu B, Charlton M, Brunsdon C, Harris P. 2013. GWmodel: an R package for exploring

559 spatial heterogeneity using geographically weighted models. arXiv preprint arXiv: 1306.0413.

560 Gómez-Díaz E, González-Solís J. 2007. Geographic assignment of seabirds to their origin:

561 combining morphologic, genetic, and biogeochemical analyses. Ecological Applications 17:

562 1484-1498.

563 Harvey MJ, Altenbach JS, Best TL. 2011. Bats of the United States and Canada. JHU Press.

564 Hayes CR, Gumbert M, Whitaker JO, Elliott CL, Dodd LE. 2019. Spatial and Temporal

565 Variation in the Diet of the Eastern Red Bat in Kentucky. Journal of the Kentucky Academy of

566 Science 79: 12-17.

567 Hayes MA. 2013. Bats killed in large numbers at United States wind energy

568 facilities. BioScience 63: 975-979. 
569 Hayes MA, Hooton LA, Gilland KL, Grandgent C, Smith RL, Lindsay SR, Collins JD,

570 Schumacher SM, Rabie PA, Gruver JC, Goodrich-Mahoney J. 2019. A smart curtailment

571 approach for reducing bat fatalities and curtailment time at wind energy facilities. Ecological

572 Applications 29: p.e01881.

573 Hayes G, Wiles GJ. 2013 Washington bat conservation plan. Washington Department of Fish 574 and Wildlife, Olympia, Washington. 138+vii pp.

575 Hernout BV, McClean CJ, Arnold KE, Walls M, Baxter M, Boxall AB. 2016. Fur: a non-

576 invasive approach to monitor metal exposure in bats. Chemosphere 147: 376-381.

577 Hickey MBC, Acharya L, Pennington S. 1996. Resource partitioning by two species of

578 vespertilionid bats (Lasiurus cinereus and Lasiurus borealis) feeding around street

579 lights. Journal of Mammalogy 77: 325-334.

580 Hickey MBC, Fenton MB, MacDonald KC, Soulliere C. 2001. Trace elements in the fur of bats

581 (Chiroptera: Vespertilionidae) from Ontario and Quebec, Canada. Bulletin of Environmental

582 Contamination and Toxicology 66: 699-706.

583 Hobson KA, Van Wilgenburg SL, Faaborg J, Toms JD, Rengifo C, Sosa AL, Aubry Y, Brito

584 Aguilar R. 2014. Connecting breeding and wintering grounds of Neotropical migrant songbirds

585 using stable hydrogen isotopes: a call for an isotopic atlas of migratory connectivity. Journal of

586 Field Ornithology 85: 237-257.

587 Hobson KA, Norris DR, Kardynal KJ, Yohannes E. 2019a. Animal migration: a context for

588 using new techniques and approaches. In Hobson KA, Wassenaar LI, ed. Tracking animal

589 migration with stable isotopes. Academic Press, 1-23. 
590 Hobson KA, Wassenaar LI, Bowen GJ, Courtiol A, Trueman CN, Voigt CC, West JB, McMahon

591 KW, Newsome SD. 2019b. Outlook for Using Stable Isotopes in Animal Migration Studies. In

592 Hobson KA, Wassenaar LI, ed. Tracking animal migration with stable isotopes. Academic

593 Press, 237-244.

$594 \mathrm{Hu}$ L, Fernandez DP, Cerling TE. 2018. Longitudinal and transverse variation of trace element

595 concentrations in elephant and giraffe hair: implication for endogenous and exogenous

596 contributions. Environmental Monitoring and Assessment 190: 644.

597 Irwin DE, Irwin JH, Smith TB. 2011. Genetic variation and seasonal migratory connectivity in

598 Wilson's warblers (Wilsonia pusilla): species-level differences in nuclear DNA between western

599 and eastern populations. Molecular Ecology 20: 3102-3115.

600 Kaiser HF. 1960. The application of electronic computers to factor analysis. Educational and 601 Psychological Measurement 20: 141-151.

602 Kays R, Crofoot MC, Jetz W, Wikelski M. 2015. Terrestrial animal tracking as an eye on life and 603 planet. Science 348: p.aaa2478.

604 Kunz TH, Arnett EB, Cooper BM, Erickson WP, Larkin RP, Mabee T, Morrison ML, Strickland 605 MD, Szewczak JM. 2007a. Assessing impacts of wind-energy development on nocturnally active 606 birds and bats: a guidance document. The Journal of Wildlife Management 71: 2449-2486.

607 Kunz TH, Arnett EB, Erickson WP, Hoar AR, Johnson GD, Larkin RP, Strickland MD, Thresher 608 RW, Tuttle MD. 2007b. Ecological impacts of wind energy development on bats: questions, 609 research needs, and hypotheses. Frontiers in Ecology and the Environment 5: 315-324. 
610 Lehnert LS, Kramer-Schadt S, Schönborn S, Lindecke O, Niermann I, Voigt CC. 2014. Wind

611 farm facilities in Germany kill noctule bats from near and far. PloS one 9: e103106.

612 Lehnert LS, Kramer-Schadt S, Teige T, Hoffmeister U, Popa-Lisseanu A, Bontadina F,

613 Ciechanowski M, Dechmann DK, Kravchenko K, Presetnik P, Starrach M. 2018. Variability and

614 repeatability of noctule bat migration in Central Europe: evidence for partial and differential

615 migration. Proceedings of the Royal Society B, 285: 20182174.

616 Lin T, Chen X, Li B, Chen P, Guo M, Zhou X, Zhong S, Cheng X. 2019. Geographical origin

617 identification of Spodoptera litura (Lepidoptera: Noctuidae) based on trace element profiles

618 using tobacco as intermedium planted on soils from five different regions. Microchemical

619 Journal 146: 49-55.

620 Morningstar D, Sandilands A. 2019. Summer movements of a radio-tagged Hoary Bat (Lasiurus 621 cinereus) captured in southwestern Ontario. The Canadian Field-Naturalist 133: 125-129.

622 Nelson DM, Braham M, Miller TA, Duerr AE, Cooper J, Lanzone M, Lemaitre J, Katzner TE. 623 2015. Stable hydrogen isotopes identify leapfrog migration, degree of connectivity and summer 624 distribution of Golden Eagles in eastern North America. Condor 117: 414-429.

625 Newbern JL, Whidden HP. 2019. Dietary analysis of three migratory bats in eastern

626 Pennsylvania. Journal of the Pennsylvania Academy of Science 93: 26-36.

627 Norris DR, Marra PP. 2007. Seasonal interactions, habitat quality, and population dynamics in 628 migratory birds. The Condor 109: 535-547.

629 Ohio Bat Conservation Plan. 2018. Ohio Bat Action Team, Columbus, OH. 
630 Orłowski G, Siebielec G, Kasprzykowski Z, Dobicki W, Pokorny P, Wuczyński A, Polechoński 631 R, Mazgajski TD. 2016. Effect of spatial resolution of soil data on predictions of eggshell trace 632 element levels in the Rook Corvus frugilegus. Environmental Pollution 219: 288-295.

633 Ossa G, Kramer-Schadt S, Peel AJ, Scharf AK, Voigt CC. 2012. The movement ecology of the 634 straw-colored fruit bat, Eidolon helvum, in sub-Saharan Africa assessed by stable isotope ratios. 635 PLoS One 7: e45729.

636 Oyoo-Okoth E, Admiraal W, Osano O, Kraak MH. 2012. Element profiles in hair and nails of 637 children reflect the uptake from food and the environment. Environmental Toxicology and 638 Chemistry 31: 1461-1469.

639 Pearce J, Ferrier S. 2000. Evaluating the predictive performance of habitat models developed 640 using logistic regression. Ecological Modelling 133: 225-245.

641 Poesel A, Nelson DA, Gibbs HL, Olesik JW. 2008. Use of trace element analysis of feathers as a 642 tool to track fine-scale dispersal in birds. Behavioral Ecology and Sociobiology 63: 153-158.

643 Popa-Lisseanu AG, Sörgel K, Luckner A, Wassenaar LI, Ibáñez C, Kramer-Schadt S, 644 Ciechanowski M, Görföl T, Niermann I, Beuneux G, Mysłajek RW. 2012. A triple-isotope 645 approach to predict the breeding origins of European bats. PLoSONE 7.

646 Pylant CL, Nelson DM, Keller SR. 2014. Stable hydrogen isotopes record the summering 647 grounds of eastern red bats (Lasiurus borealis). PeerJ 2: p.e629.

648 Pylant CL, Nelson DM, Fitzpatrick MC, Gates JE, Keller SR. 2016. Geographic origins and 649 population genetics of bats killed at wind-energy facilities. Ecological Applications 26: 13816501395. 
651 R Core Team. 2019. R: A language and environment for statistical computing. R Foundation for

652 Statistical Computing, Vienna, Austria. URL https:/www.R-project.org/.

653 Rahman A, Talukdar NR, Choudhury P. 2020. Assessing some essential trace elements

654 concentration in micro chiropteran bat (Megaderma lyra): A study in Barak Valley of Assam, 655 India. Environmental Chemistry and Ecotoxicology 2: 56-63.

656 Reimer JP, Baerwald EF, \&Barclay RM. 2010. Diet of hoary (Lasiurus cinereus) and silver657 haired (Lasionycteris noctivagans) bats while migrating through southwestern Alberta in late 658 summer and autumn. The American Midland Naturalist 164: 230-237.

659 Rodhouse TJ, Rodriguez RM, Banner KM, Ormsbee PC, Barnett J, Irvine, KM. 2019. Evidence 660 of region-wide bat population decline from long-term monitoring and Bayesian occupancy 661 models with empirically informed priors. Ecology and Evolution 9: 11078-11088.

662 Ruegg KC, Anderson EC, Harrigan RJ, Paxton KL, Kelly JF, Moore F, Smith TB. 2017. Genetic 663 assignment with isotopes and habitat suitability (GAIAH), a migratory bird case study. Methods 664 in Ecology and Evolution 8: 1241-1252.

665 Rundel CW, Wunder MB, Alvarado AH, Ruegg KC, Harrigan R, Schuh A, Kelly JF, Siegel RB, 666 DeSante DF, Smith TB, Novembre J. 2013. Novel statistical methods for integrating genetic and 667 stable isotope data to infer individual-level migratory connectivity. Molecular Ecology 22: 4163 6684176.

669 Sastre J, Vidal M, Rauret G, Sauras T. 2001. A soil sampling strategy for mapping trace element 670 concentrations in a test area. Science of the Total Environment 264: 141-152. 
671 Schorr RA, Ellison LE, Lukacs PM. 2014. Estimating sample size for landscape-scale mark672 recapture studies of North American migratory tree bats. Acta Chiropterologica 16: 231-239.

673 Seifert N, Ambrosini R, Bontempo L, Camin F, Liechti F, Rubolini D, Scandolara C, Saino N, 674 Hahn S. 2018. Matching geographical assignment by stable isotopes with African non-breeding 675 sites of barn swallows Hirundo rustica tracked by geolocation. PloSONE 13.

676 Smith DB, Cannon WF, Woodruff LG, Garrett RG, Klassen R, Kilburn JE, Horton JD, King HD, 677 Goldhaber MB, Morrison JM. 2005. Major- and trace-element concentrations in soils from two 678 continental-scale transects of the United States and Canada. U. S. Geological Survey.

679 Smith DB, Cannon WF, Woodruff LG, Solano F, Ellefsen KJ. 2014, Geochemical and 680 mineralogical maps for soils of the conterminous United States: U.S. Geological Survey Open681 File Report 2014-1082: 1-386

682 Sovic MG, Carstens BC, Gibbs HL. 2016. Genetic diversity in migratory bats: Results from 683 RADseq data for three tree bat species at an Ohio windfarm. PeerJ 4: p.e1647.

684 Sullivan BL, Wood CL, Iliff MJ, Bonney RE, Fink D, Kelling S. 2009. eBird: a citizen-based 685 bird observation network in the biological sciences. Biological Conservation 142: 2282-2292.

686 Sullivan AR, Bump JK, Kruger LA, Peterson RO. 2012. Bat-cave catchment areas: using stable 687 isotopes $(\delta \mathrm{D})$ to determine the probable origins of hibernating bats. Ecological Applications 22: $688 \quad 1428-1434$.

689 Szép T, Hobson KA, Vallner J, Piper SE, Kovács B, Szabó DZ, Møller AP. 2009. Comparison of 690 trace element and stable isotope approaches to the study of migratory connectivity: an example 
691 using two hirundine species breeding in Europe and wintering in Africa. Journal of Ornithology 692 150: 621.

693 Tigar B, Hursthouse AS. 2016. Applying biogeochemistry to identify the geographic origins of 694 insects-a model using Prostephanus truncatus. Journal of Environmental Studies 2: 9.

695 Tonra CM, Both C, Marra PP. 2014. Incorporating site and year-specific deuterium ratios $(\delta 2 \mathrm{H})$

696 from precipitation into geographic assignments of a migratory bird. Journal of Avian Biology 46: $697 \quad 266-274$.

698 United States Enivronmental Protection Agency. 2003. Mercury Preservation Techniques.

699 Vander Zanden, HB, Nelson DM, Wunder MB, Conkling TJ, Katzner T. 2018. Application of 700 isoscapes to determine geographic origin of terrestrial wildlife for conservation and management. 701 Biological Conservation 228: 268-280.

702 Vaughan N. 1997. The diets of British bats (Chiroptera). Mammal Review 27: 77-94.

703 Voigt CC, Popa-Lisseanu AG, Niermann I, Kramer-Schadt S. 2012. The catchment area of wind 704 farms for European bats: a plea for international regulations. Biological Conservation 153: 8070586.

706 Voigt CC, Lehnert LS. 2019. Tracking of movements of terrestrial mammals using stable 707 isotopes. In Hobson KA, Wassenaar LI, ed. Tracking animal migration with stable isotopes. 708 Academic Press, 117-135.

709 Vonhoff MJ, Russell AL. 2015. Genetic approaches to the conservation of migratory bats: a 710 study of the eastern red bat (Lasiurus borealis). PeerJ 3: p.e983. 
711 Wilson HG. 2017. Diet And Activity Patterns of Five Bat Species in North-Central Kansas

712 [master's thesis]. Fort Hayes State University

713 Wunder MB, Norris DR. 2019. Design and Analysis for Isotope-Based Studies of Migratory

714 Animals. In Hobson KA, Wassenaar LI, ed. Tracking animal migration with stable isotopes.

715 Academic Press, 191-206.

716 Zocche JJ, Leffa DD, Damiani AP, Carvalho F, Mendonça RÁ, Dos Santos CEI, Boufleur LA,

717 Dias JF, de Andrade VM. 2010. Heavy metals and DNA damage in blood cells of insectivore

718 bats in coal mining areas of Catarinense coal basin, Brazil. Environmental Research 110: 684-

719691. 


\section{Figure 1}

Sampling Distribution for L. borealis.

Distribution of eastern red bat samples used for validation. Samples were obtained from Smithsonian Museum of Natural History. The brown shaded area represents the current IUCN Red List range (Arroyo-Cabrales et al., 2016). Map outline of countries generated using 'maps' R package (Becker et al. 2018).

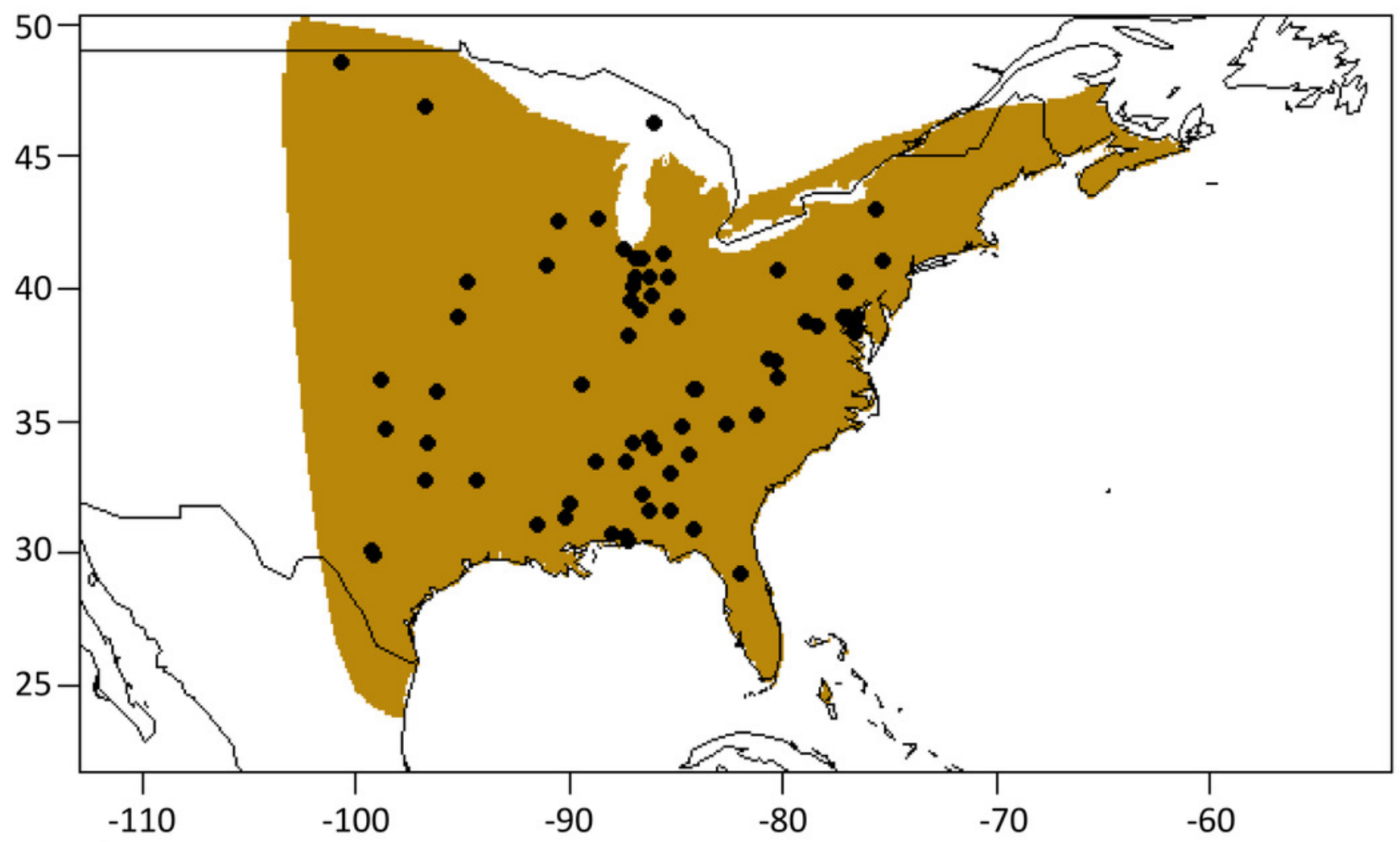


Figure 2

Basemap generated from SPCA results for PC1.

Colors represent component scores, to which individuals can be assigned based on the component scores for their fur. Map outline of countries generated using 'maps' R package (Becker et al. 2018). 


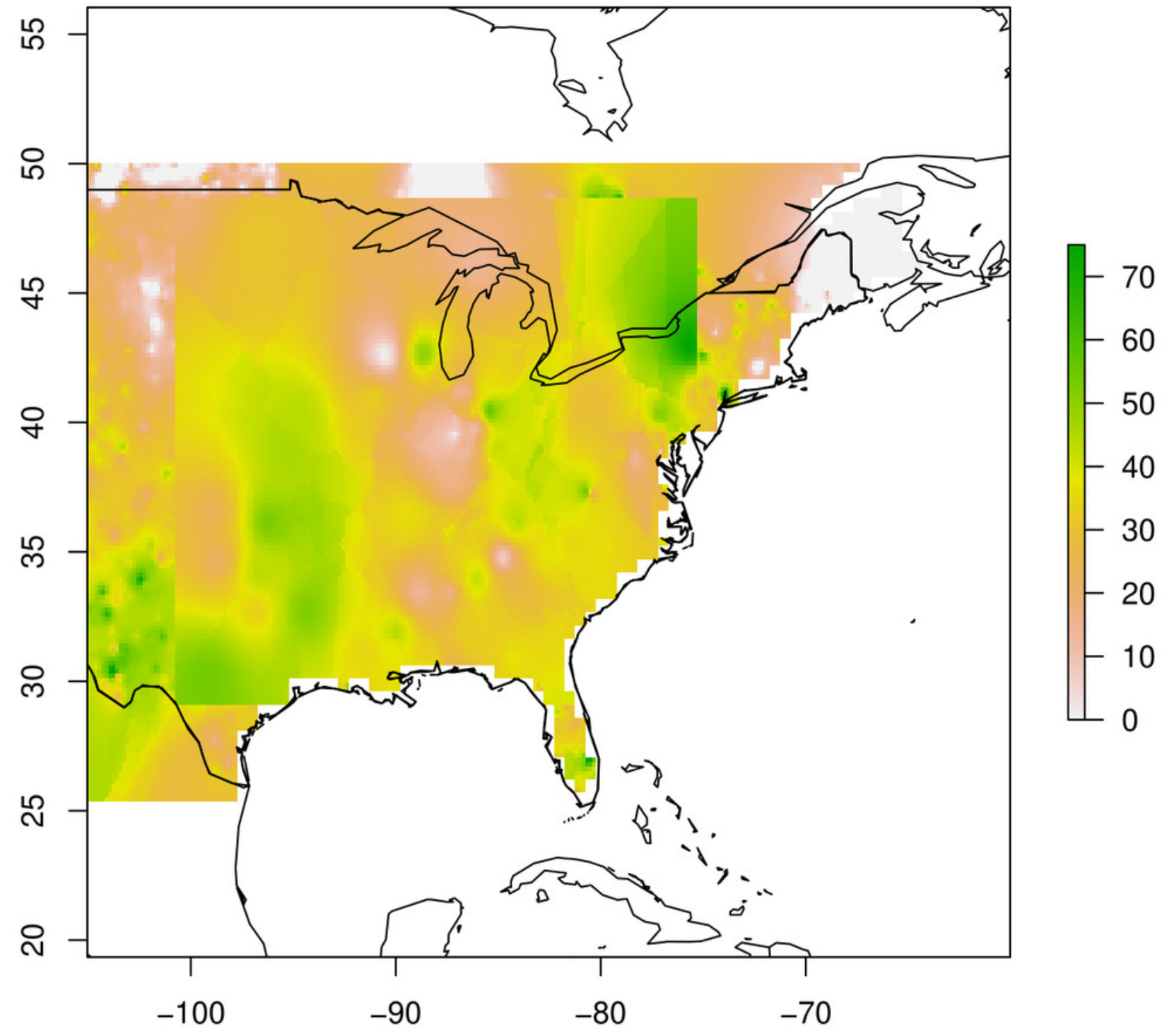




\section{Figure 3}

Sample prediction surfaces generated.

Prediction surfaces (scale bars ranging from $0 \%$ probability to $100 \%$ probability) for three different bats. Black dot represents sampling location. A and B correspond to correct assignment, while $\mathrm{C}$ is an incorrect assignment of origin. Map outline of countries generated using 'maps' R package (Becker et al. 2018).
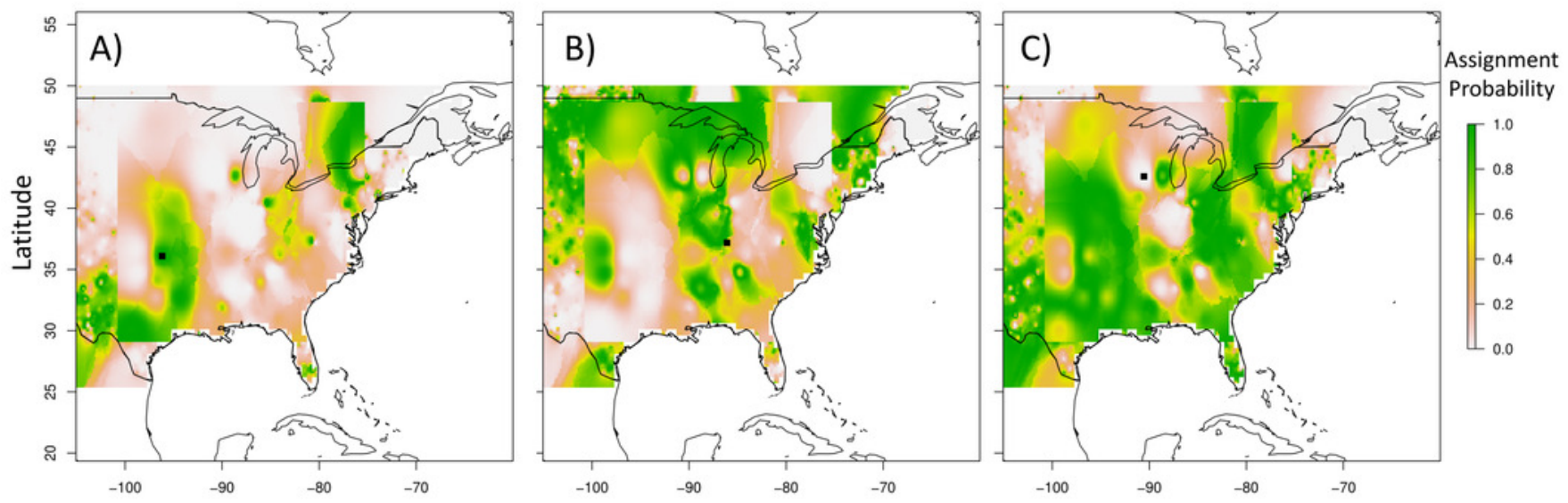


\section{Table 1 (on next page)}

Mean Concentrations and Deviations for Trace Elements.

Mean concentrations of trace elements in L. borealis fur from across their range with the standard deviation (SD) also reported. For each element the correlation between fur and soil (using $\mathrm{R}^{2}$ ) concentrations are presented with the associated $\mathrm{p}$-value. Those that are significant $(p<0.05)$ are designated with an ' $*$ '. 


\begin{tabular}{|c|c|c|c|c|}
\hline & Mean & STD & Soil/ Fur $\mathrm{R}^{2}$ & Soil/ Fur $\mathrm{p}$-value \\
\hline $\mathrm{Al}(\mathrm{ppb})$ & 18.814 & 15.537 & 0.010 & 0.21 \\
\hline $\mathrm{Ni}(\mathrm{ppb})$ & 2.254 & 2.663 & 0.010 & 0.45 \\
\hline $\mathrm{Cu}(\mathrm{ppb})$ & 6.237 & 3.053 & 0.015 & 0.35 \\
\hline $\mathrm{Rb}(\mathrm{ppb})$ & 0.652 & 0.352 & 0.073 & $0.04^{*}$ \\
\hline Y (ppb) & 0.378 & 0.199 & 0.062 & 0.06 \\
\hline Mo (ppb) & 1.585 & 0.805 & 0.154 & $0.01^{*}$ \\
\hline $\operatorname{Sn}(p p b)$ & 4.225 & 5.169 & 0.071 & $0.04^{*}$ \\
\hline $\mathrm{Ba}(\mathrm{ppb})$ & 5.415 & 3.010 & 0.001 & 0.77 \\
\hline Cs (ppb) & 0.914 & 2.609 & 0.002 & 0.34 \\
\hline $\mathrm{Ce}(\mathrm{ppb})$ & 0.325 & 0.159 & 0.001 & 0.62 \\
\hline $\mathrm{Hg}(\mathrm{ppb})$ & 4.777 & 4.431 & 0.004 & 0.63 \\
\hline $\mathrm{Mg}(\mathrm{ppb})$ & 51.891 & 24.056 & 0.120 & 0.46 \\
\hline $\mathrm{Mn}(\mathrm{ppb})$ & 1.297 & 0.677 & 0.021 & 0.27 \\
\hline $\mathrm{Fe}(\mathrm{ppb})$ & 65.486 & 80.390 & 0.001 & 0.78 \\
\hline
\end{tabular}




\section{Table 2 (on next page)}

sPCA loadings and weights for each element.

sPCA loadings and weights (loading*average element value) for each element onto the first three principle components, as determined using 'gwpca' in R. The proportion of the variance, or the amount of variation explained by each principle component, is at the bottom of the table. 


\begin{tabular}{ccccccc}
\hline $\mathrm{Al}$ & 0.07 & 1.39 & 0.15 & 2.77 & 0.39 & 7.41 \\
$\mathrm{Ni}$ & 0.23 & 0.51 & -0.06 & -0.12 & -0.17 & -0.38 \\
$\mathrm{Cu}$ & 0.21 & 1.28 & 0.06 & 0.35 & 0.21 & 1.32 \\
$\mathrm{Rb}$ & 0.27 & 0.18 & -0.05 & -0.03 & -0.18 & -0.12 \\
$\mathrm{Y}$ & 0.27 & 0.10 & -0.06 & -0.02 & -0.19 & -0.07 \\
$\mathrm{Mo}$ & 0.27 & 0.43 & -0.04 & -0.06 & -0.19 & -0.30 \\
$\mathrm{Sn}$ & 0.15 & 0.61 & -0.03 & -0.13 & 0.09 & 0.38 \\
$\mathrm{Ba}$ & 0.28 & 1.51 & 0.02 & 0.12 & 0.04 & 0.23 \\
$\mathrm{Cs}$ & -0.03 & -0.03 & 0.02 & 0.02 & 0.08 & 0.08 \\
$\mathrm{Ce}$ & 0.27 & 0.09 & -0.06 & -0.02 & -0.16 & -0.05 \\
$\mathrm{Hg}$ & 0.16 & 0.78 & 0.06 & 0.26 & 0.30 & 1.45 \\
$\mathrm{Mg}$ & 0.18 & 9.55 & -0.01 & -0.52 & 0.03 & 1.71 \\
$\mathrm{Mn}$ & 0.06 & 0.08 & 0.53 & 0.69 & -0.18 & -0.23 \\
$\mathrm{Fe}$ & -0.02 & -1.18 & 0.56 & 36.61 & -0.15 & -10.08 \\
\hline \hline Proportion of Variance & 0.50 & \multicolumn{3}{c}{0.12} & & 0.10
\end{tabular}

\section{PC2}




\section{Table 3 (on next page)}

Locations and results for 15 independent samples.

Locations and prediction information for 15 test individuals and the training dataset following a leave-three-out approach. We report the PC values for each individual, the prediction probability at the sampling location, and the percent of $L$. borealis range predicted. 


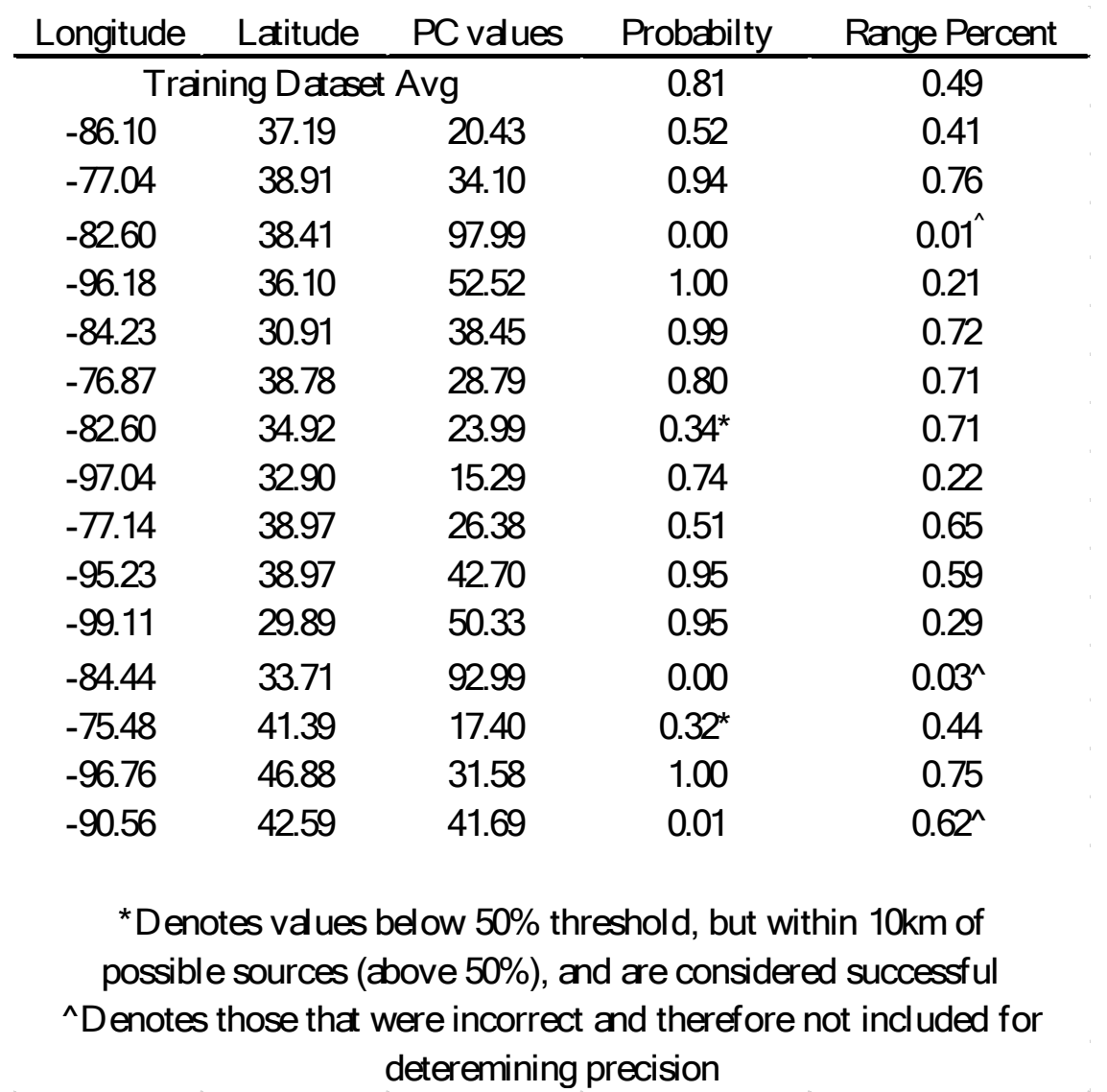

